SCIENTIFIC LETTER

\title{
A trial of early discharge with homecare compared to conventional hospital care for patients undergoing coronary artery bypass grafting
}

\author{
J E Booth, J A Roberts, M Flather, D L Lamping, R Mister, M Abdalla, H Goodman, E Peters, \\ J Pepper
}

$\mathrm{T}$ he UK has one of the longest waiting lists for coronary artery bypass grafting (CABG). In 1999-2000, 24798 CABG procedures were performed ${ }^{1}$ at a typical cost of $£ 4956,{ }^{2}$ leading to total direct costs in excess of $£ 122$ million. Early discharge programmes have been introduced as a strategy to reduce hospital costs, increase the throughput of patients and decrease waiting list times. Early studies have reported reductions in hospital length of stay (LOS) and hospital costs, without an increase in complication rates. ${ }^{3-6}$ There are concerns that early discharge programmes may increase morbidity after discharge and increase the demand on community health care resources, simply moving costs downstream without any true overall savings. The Royal Brompton Hospital has introduced a new early discharge programme that contained enhanced preoperative preparation, planned early discharge, and specialist homecare. We report the results of a randomised trial to compare costs, clinical outcomes, and quality of life in an early discharge homecare programme compared to conventional hospital care.

\section{METHODS}

Patients were eligible if they required first time isolated bypass surgery, had a carer available to stay, and lived within the travel area of the homecare team. This study was carried out in a specialist tertiary referral hospital. Both patient and carer gave written informed consent. Patients were randomised in a ratio of $1: 2$ to conventional hospital care or early discharge. We followed patients for three months after surgery. Patients in the conventional care group were admitted one day before surgery and planned discharge was $7( \pm 1)$ days after surgery. Early discharge patients attended a pre-admission clinic, admission was the same day as surgery and planned discharge was $4( \pm 1)$ days after surgery. Specialist hospital based nurses provided homecare.

The main outcomes were length of hospital stay, inhospital clinical events, total costs, re-admission rates, and quality of life at 12 weeks. We estimated costs for each patient and included LOS, homecare nurse, physiotherapist, occupational therapist, drugs, tests, investigations, general practitioner and community nurse visits, and hospital visits. Unit costs were obtained or estimated from Trust financial figures and published data. We evaluated quality of life using the UK version of the medical outcomes study short form 36 $(\mathrm{SF}-36) .^{7}$

\section{RESULTS}

A total of 97 patients were randomised to conventional hospital care $(\mathrm{n}=32)$ or early discharge $(\mathrm{n}=65)$. LOS was shorter in patients in the early discharge compared with conventional care group (5.3 $v 8.0$ days, p $<0.001)$ and $80 \%$ of patients were admitted on the day of surgery. The rate of in-hospital clinical events, re-admission rates, and quality of life at 12 weeks were similar in the two groups (table 1).

One patient in the early discharge group stayed in hospital for 75 days because of multiple complications and incurred a hospital cost of $£ 69593$ and a 12 week follow up cost of $£ 321$. This patient's data were censored from the main cost analysis. Hospital costs (including pre-admission clinic and homecare costs in the early discharge group) and costs for primary care surgery/home visits and all hospital visits following discharge were similar between the two groups (table 1). The costs of re-admissions were higher in the conventional hospital care group compared to the early

Table 1 Clinical outcomes, quality of life, and cost, in patients randomised to conventional hospital care or an early discharge programme

\begin{tabular}{|c|c|c|c|c|c|}
\hline & $\begin{array}{l}\text { Early } \\
\text { discharge }\end{array}$ & $\begin{array}{l}\text { Hospital } \\
\text { care }\end{array}$ & $\begin{array}{l}\text { Difference between } \\
\text { cost of early } \\
\text { discharge and } \\
\text { hospital care }\end{array}$ & ${ }^{*} 95 \% \mathrm{Cl}$ & p Value \\
\hline $\begin{array}{l}\text { In-hospital clinical events } \\
\text { SF-36 PCS } 12 \text { weeks } \\
\text { SF-36 MCS } 12 \text { weeks } \\
\text { Total hospital LOS (days) } \\
\text { †Hospital costs for CABG* } \\
\text { Costs of re-admissions } \\
\text { Primary care costs } \\
\text { Costs of hospital visits } \\
\ddagger \text { Total costs at } 12 \text { weeks }\end{array}$ & $\begin{array}{l}20 / 65(30 \%) \\
47.4(11.8) \\
48.9(8.2) \\
5.3(2.68) \\
£ 5644 \\
£ 185 \\
£ 58 \\
£ 240 \\
£ 6127\end{array}$ & $\begin{array}{l}8 / 32(25 \%) \\
49.0(11.7) \\
49.2(8.6) \\
8.0(1.78) \\
£ 5629 \\
£ 492 \\
£ 63 \\
£ 198 \\
£ 6381\end{array}$ & $\begin{array}{l}-0.5 \\
0.6 \\
£ 15 \\
£-306 \\
£-5 \\
£ 42 \\
£-254\end{array}$ & $\begin{array}{l}(-5.8 \text { to } 4.8) \\
(-2.7 \text { to } 3.8) \\
£-363 \text { to } 457 \\
£-758 \text { to } 61 \\
£-32 \text { to } 18 \\
£-45 \text { to } 124 \\
£-919 \text { to } 348\end{array}$ & $\begin{array}{l}0.55 \\
0.85 \\
0.73 \\
<0.001\end{array}$ \\
\hline
\end{tabular}

LOS, length of stay; MCS, mental component score; PCS, physical component score

*95\% Cl for costs obtained using Bootstrap method; thospital costs for the early discharge group include preadmission clinic, in-hospital and homecare costs; łtotal costs include in-hospital, homecare, primary care, readmission, and hospital visits costs. 
discharge group ( $£ 492 v £ 185)$. The total costs at 12 week follow up were higher in the conventional hospital care group compared to early discharge ( $£ 6381 v £ 6127)$.

\section{DISCUSSION}

CABG is the most common major surgical procedure performed in the UK. We have shown that a planned early discharge homecare programme offers an effective alternative care management strategy to conventional hospital care without increasing community health care costs. Hospital readmission rates, clinical events, and quality of life were similar. Our detailed cost analysis includes not only detailed hospital costs, but for the first time to our knowledge, community care costs after discharge.

The National Service Framework for coronary artery disease is expected to increase the number of CABG procedures to at least 750 per million of the population. At current growth rates this target should be met in $2005 .{ }^{8}$ An ability to meet higher targets is an important consideration. On a national level, if $20 \%(\mathrm{n}=5000)$ of patients undergoing CABG per year were treated with an early discharge programme, this could result in a saving of 13500 bed days. The number of CABG procedures is, however, limited by a number of other factors including the availability of surgeons, theatre time, and intensive care beds. If we assume that the hospital has the capacity to operate on more patients per year, then decreasing LOS allows more operations, which can reduce waiting list times. There are important organisational and funding factors that need to be addressed before the policy could impact on waiting lists for patients requiring CABG or other cardiothoracic surgery. The increased cost of treating more patients, given that the most cost intense activities are at the beginning of hospitalisation, is a matter that would need to be addressed by purchasers and providers.

Our study has some limitations. The sample size of 97 patients limited our ability to reach definitive conclusions about clinical and patient based outcomes. Our main cost analysis censors a patient that stayed in for a long time and incurred very high costs but we believe this approach is justified in this small study.
In summary, we found that an early discharge homecare programme is a viable alternative management strategy for patients requiring CABG. We believe this strategy would help achieve recommendations to move care into the community and the reduction in LOS would allow more admissions. A large multicentre study is required to determine whether this policy would have an impact on bed occupancy and waiting lists and to provide costs that are representative for the UK.

\section{Authors' affiliations}

J E Booth, M Flather, R Mister, H Goodman, E Peters, J Pepper, Royal Brompton \& Harefield NHS Trust, London, UK

J A Roberts, D L Lamping, M Abdalla, London School of Hygiene \&

Tropical Medicine, London, UK

Correspondence to: Ms Jean E Booth, Clinical Trials \& Evaluation Unit, Royal Brompton Hospital, London SW3 6NP, UK; i.booth@rbh.nthames. nhs.uk

Accepted 19 January 2004

\section{REFERENCES}

1 The Society of Cardiothoracic Surgeons of Great Britain and Ireland. National audit cardiac surgical datbase report 1999-2000. 2001.

2 NHS Executive. Reference costs 2000 technical supplement. Leeds: Department of Health, 2000.

3 Cheng DCH, Karski J', Peniston C, et al. Early tracheal extubation after coronary artery bypass graft surgery reduces cost and improves resource use. Anesthesiology 1996;85:1300-10.

4 Engelman RM, Rousou jA, Flack JE, et al. Fast-track recovery of the coronary bypass patient. Ann Thoracic Surg 1994;58:1742-6.

5 Riegel B, Gates DM, Gocka I, et al. Effectiveness of a program of early hospital discharge of cardiac surgery patients. Journal of Cardiovascular Nursing 1996;11:63-75.

6 London MJ, Schroyer LA, Jernigan V, et al. Fast-track cardiac surgery in a Department of Veterans Affairs patient population. Ann Thoracic Surg 1997;64:134-41

7 Brazier JE, Harper R, Jones NM, et al. Validating the SF-36 health survey questionnaire: new outcome measure for primary care. $B M$ 1992;305:160-4.

8 National Institute of Clinical Excellence. Guidance on the use of coronary stents. Technology Appraisal 71, 2003.

\section{ELECTRONIC PAGES}

\section{Heart Online case reports: www.heartjnl.com}

$T^{2}$

\section{Massive pulmonary artery thrombosis with haemoptysis in adults with Eisenmenger's syndrome: a clinical dilemma}

C Broberg, M Ujita, S Babu-Narayan, M Rubens, S K Prasad, J S R Gibbs, M A Gatzoulis

Although the frequency of haemoptysis in Eisenmenger's syndrome is well recognised, the high prevalence of pulmonary artery thrombus has been newly appreciated through the growing use of non-invasive imaging. Three patients with Eisenmenger's syndrome with haemoptysis are reported who underwent computed tomography pulmonary angiography and cardiovascular magnetic resonance. Each patient was found to have aneurysmal dilatation of the right pulmonary artery with large laminar thrombus. These cases illustrate a rising clinical problem in this special population-that is, how to treat and prevent large pulmonary artery thrombosis in the setting of haemoptysis. The authors discuss their approach to these cases and the known literature.

(Heart 2004;90:e63) www.heartjnl.com/cgi/content/full/90/ $11 / \mathrm{e} 63$

\section{Left atrial phaeochromocytoma}

N Moorjani, J Kuo, D Wilkins

Phaeochromocytomas of the heart are very rare. This report describes the case of a 69 year old woman presenting with persistent hypertension and a left atrial phaeochromocytoma diagnosed by ${ }^{131}$ I-metaiodobenzylguanidine scintigraphy scanning. She was successfully treated by surgical excision with the aid of cardiopulmonary bypass and perioperative $\alpha$ and $\beta$ adrenergic blockade.

(Heart 2004;90:e64) www.heartjnl.com/cgi/content/full/90/ $11 / \mathrm{e} 64$ 